Article

\title{
A Model to Estimate the Cost-Effectiveness of Water Pollution Management Strategies in Developing Countries: The Cocody Bay Case, Côte d'Ivoire
}

Vassiki Sanogo $1,2,3$

${ }^{1}$ Center for Economic Forecasting and Analysis, Florida State University, Tallahassee, FL 32306,USA; vsanogo@cefa.fsu.edu; vassikisanogo@gmail.com; vsanogo@hotmail.fr

${ }^{2}$ Université Alassane Ouattara, Bouaké BP V 18 01, Côte d'Ivoire

${ }^{3}$ Tallahassee Community College, 444 Appleyard Dr, Tallahassee, FL 32304, USA

\begin{abstract}
The pollution of the bays in Abidjan is a major concern for the Ivorian policy makers. In fact, the pollution of the bays induce high costs to the society while impacting population health dramatically. As a result, pollution reduction management of production activities has been undertaken in the Cocody Bay area. To our knowledge, no study has yet proposed a model to evaluate the cost-effectiveness of these pollution management strategies. A cost-effectiveness model, based on Monte Carlo simulation, was developed to assess the economic and environmental impacts of various scenarios characterized by a set of production practices, both in the short term and in the long term. The authors discuss the steps and input parameters of the model presented. The proposed model may serve as the basis for identifying an optimal production scenario defined as the scenario with the best incremental cost-effectiveness ratio considering a willingness to pay (WTP) threshold. The WTP, to be estimated based on the gross domestic product of Côte d'Ivoire, represents the opportunity costs associated with selecting the optimal scenario. The current framework can also be applied to other settings facing similar challenge.
\end{abstract}

Keywords: pollution; cost-effectiveness analysis; Cocody; environmental policies; environmental constraints 


\section{Introduction}

Recent studies on the Ebrie Lagoon report increasing bay pollution levels in the district of Abidjan, Côte d'Ivoire, West Africa [cf .: the Ivorian Anti-Pollution Centre (CIAPOL )]. These studies have established that this pollution has various origins, the main ones being natural, anthropogenic and technical.

In response to the effect of the polluted bays on population health and economic activities, in 2011 the Ivorian policy makers announced measures aimed at managing the pollution of the Abidjan lagoon, particularly the Cocody Bay. [cf.: Plan d'action pour la dépollution et la réhabilitation de la baie de Cocody, juillet 2011, National Bureau of Technical Studies and Development (BNETD)]. To our knowledge, no study has yet evaluated the impact of these pollution management practices from an economic perspective. Such a study should account for the complex interactions between the economy, human activities and the sanitation system in Abidjan, not to mention the stochastic nature of climatic factors and the lack of reliable data.

McSweeny and Shortle (1990) used a cost-effectiveness approach to conduct this type of study. Their approach took into consideration the impact of uncertainty in the estimation of the costs and the effectiveness of pollution management practices. The authors accounted for the uncertainty caused by factors related to runoff rates through the use of random variables. Bystrom et al (2000) used a similar approach to study the impact of an appropriate water and drainage system (waste and runoff) to control pollution. The main limitation of these studies the crude manner in which uncertainty was included into the models, by the use of simple probability functions. The uncertainty due to climate change and lack of data were not dissociated within the functions. Finally, the level of uncertainty was set arbitrarily through the use of random variables. 
In this study, we propose a model to assess the economic and environmental impacts of different scenarios characterized by a set of pollution management practices in the watershed of the Cocody Bay. This model will include climatic variables and errors attached to the production models of the pollution management scenarios. The ultimate goal is to enable the identification of an optimal scenario for pollution management.

\section{Methods}

A cost-effectiveness framework was developed to facilitate the modelling of the costs and outcomes associated with the pollution management strategies applied to the Cocody Bay, in a context of scarcity of reliable data. The ultimate goal of this model is to simulate the incremental cost-effectiveness ratios (ICER) of the comparison of each pollution management strategy to the current pollution management strategy (reference scenario) applied to the Cocody Bay. This framework consists of different steps that are described in the next sections.

\section{Competing Alternatives}

The first step in our approach consists of identifying the competing alternatives considered in the cost-effectiveness analysis. These alternatives are the pollution management strategies applied to the Cocody Bay. In the absence of evidence on the costs and effects of activities that pollute the bay, it is recommended to develop scenarios to represent (proxy) the pollution management strategies. The development of these scenarios should be done according to the characteristics of the activities that pollute the Cocody Bay.

\section{Perspective of the analysis}

The choice of the perspective of the analysis is of paramount importance as it drives the identification of the resource use and costs to be considered in the analysis. In the current 
case, the perspective of the Ivorian policy makers was selected since they are interested in investing in the best strategy to manage the pollution of the Cocody Bay. As such, it is important that the analysis reflects the costs that might be incurred by the policy makers to achieve their goal.

\section{Temporal framework}

The time horizon should be long enough to capture all the relevant costs and effects of the competing alternatives on the Cocody bay. A five-year temporal framework was selected.

\section{Model input parameters}

\section{Resource use and costs associated with the implementation of the competing scenarios}

The estimation of the costs of the scenarios (s) is a function of 14 activities (k) that impact the pollution level of the Cocody Bay (see CIAPOL). These costs vary depending on the year (t). Let $v_{\text {stk }}$ be the vector of the characteristics that describe the activities impacting the pollution level of the Cocody Bay with $\mathrm{s} \in\{1,2, \ldots, \mathrm{S}\}, \mathrm{t} \in\{1,2, \ldots, \mathrm{T}\}$ and $\mathrm{k} \in\{1,2, \ldots, \mathrm{K}\}$. For each $v_{s t k}$ value, we calculate a return $r_{s t k}$ and an index of quality of goods and services $q_{s t k}$ obtained from the activities influencing the pollution level of the Cocody Bay. $r_{\text {stk }}$ and $q_{s t k}$ are calculated based on the production models of these activities. The advantage of using production models is that these models take into account the uncertainty inherent in production processes. This is achieved by defining random variables to describe the errors of production models and any other sources of uncertainty. As a result, we introduce in to our function errors $\varepsilon^{r}{ }_{s t k}$ and $\varepsilon^{q}{ }_{s t k}$ respectively associated with the values of $r_{s t k}$ and $q_{s t k}$.

The generated revenue per square meter of activities in the Cocody Bay obtained during the year $(\mathrm{t})$, in the field of activity $(\mathrm{k})$, and when the scenario $(\mathrm{s})$ is applied, are noted $\left(m_{s t k}\right)$ 
and are calculated using factors of the production models. In other words, this calculation involveing $r_{s t k}$ and $q_{s t k} . m_{s t k}$ is determined by using the function (f) such that:

$$
m_{s t k}=f\left(v_{s t k}, r_{s t k}+\varepsilon_{s t k}^{r}, q_{s t k}+\varepsilon_{s t k}^{q}\right)
$$

Several expressions of the function (f) exist. These expressions differ depending on the value of the price of products. Since $r_{s t k}$ and $q_{s t k}$ are defined as stochastic variables, $m_{s t k}$ will be treated as a stochastic variable. Let $\pi_{s t}$ be all revenue generating activities in the Cocody Bay for the scenario (s) and year ( $\mathrm{t}) . \pi_{s t}$ is defined as follows:

$\pi_{s t}=\sum_{k=1}^{K} m_{s t k} * x_{k}$ with $x_{k}$ defined as the area occupied by the $\mathrm{k}^{\text {th }}$ activity in the Cocody Bay. Costs are calculated relative to the reference scenario $(s=1)$. Thus, the cost of the scenario (s) $C_{s t}$ in the year $(\mathrm{t})$ is obtained such that:

$C_{s t}=\pi_{s t}-\pi_{1 t}$

This formula can be rearranged such that:

$C_{s t}=\sum_{k=1}^{K} m_{1 t k} * x_{k}-\sum_{k=1}^{K} m_{s t k} * x_{k}$ with $m_{1 t k}$ and $\pi_{1 t}$ representing the revenue generated for the year $(\mathrm{t})$ and activity $(\mathrm{k})$ respectively (for a unit of occupied space in the bay, when the base scenario applies). The total cost for a scenario (s) over the entire time horizon (5 years) $C_{S}$ is calculated as:

$$
C_{s}=\sum_{t=1}^{T} C_{s t}
$$

Since the revenue generated by the activities $(\mathrm{k})$ are defined as stochastic variables, $C_{s t}$ and $C_{s}$ are also considered stochastic variables.

\section{Estimation of pollution levels induced in the Cocody bay}

\section{Concentrations of pollutants generated by each scenario}

The concentration of pollutants in the bay is defined as the annual level of pollutants recorded for the year ( $\mathrm{t}$ ) when the scenario (s) is applied to the bay. Denoted $p_{s t}$, this concentration is 
predicted based on the climatic characteristics and type of activities in the bay, using production models. $p_{s t}$ is therefore calculated as follows:

$p_{s t}=\frac{\sum_{k=1}^{K}\left(l_{s t k}+\varepsilon_{s t k}^{l}\right)}{d_{t}}$, with $l_{s t k}$ and $d_{t}$ respectively representing the annual $(\mathrm{t})$ amount of pollutants discharged into the bay per activity (k) (when the scenario (s) is applied), and the volume of water in the bay for the corresponding year $(\mathrm{t})$. In this study, we intend to develop realistic prediction models that would approximate the true value of $l_{s t k}$. Prediction errors are described by the random term $\varepsilon_{s t k}^{l}$. Prediction errors on the volume of water in the Cocody Bay are negligible since this volume is measured accurately every year. The concentration of water pollutants in the Cocody Bay over the entire time horizon ( 5 years) is defined by:

$$
p_{s}=\sum_{t=1}^{T} p_{s t}
$$

Since the $p_{s t}$ associated with the activities (k) are defined as stochastic variables, $p_{s}$ also obeys a stochastic law.

\section{Estimating and expressing the cost-effectiveness results}

The estimation of the ICERs is shown in equation 1.

\section{Equation 1.}

$\operatorname{ICER}=\frac{C_{s}(\text { Alternative scenario })-C_{s}(\text { Reference scenario })}{p_{s}(\text { Alternative scenario })-p_{s}(\text { Reference scenario })}$

Where $C_{s}$ represents the total cost for a scenario (s) and $p_{s}$ is the concentration of water pollutants in the Cocody Bay over the entire time horizon (5 years). The optimal scenario, defined as the scenario with the best incremental cost-effectiveness ratio, considering a willingness to pay (WTP) threshold, is recommended. The WTP, estimated based on the 
gross domestic product of Côte d'Ivoire, represents the opportunity costs attached with selecting the optimal scenario.

\section{Robustness analyses}

Robustness analyses can be conducted to assess the impact of model uncertainty on the selection of the optimal strategy or alternative. In this approach, robustness analysis can be carried-out by imposing time related constraints to the model. These constraints are presented below.

\section{Short-term constraints}

The purpose of imposing short-term constraints to the proposed model reflects the desire to quickly reduce the levels of pollution in the Cocody Bay. The first constraint applied to the model is expressed as follows: $E\left(p_{s t} / t\right) \leq \alpha m g l^{-1}, \forall t \in\{1, \ldots, T\}$ with $\alpha m g l^{-1}$ corresponding to the accepted pollution norm in the Cocody Bay. An additional constraint is imposed on the model that takes into account the possibility of errors in production models, and is expressed such that: $P\left(p_{s t} \leq \alpha m g l^{-1} / t\right) \geq \rho, \forall t \in\{1, \ldots, T\}$ with $\mathrm{P}$ being the probability of errors in production models.

\section{Concluding remarks}

In this paper we proposed a cost-effectiveness framework for the assessment of water pollution management strategies in developing countries, with the Cocody Bay, Abidjan, Côte d'Ivoire as an example. The proposed model allows for the identification of an optimal scenario for water pollution management strategies. This optimal scenario is defined as a scenario that minimizes the mean expected costs $E\left(\bar{C}_{s}\right)$ and generates the lowest mean pollutant concentration levels $\bar{p}_{s}$. This approach has the advantage of taking into account the 
constraints on the concentration of pollutants in the water, defined in accordance with different variations between years in the prediction of production models of the activities $(\mathrm{K})$ that pollute the bay. In addition, the proposed approach includes the characterization of uncertainty in modelling through robustness analyses, which is likely to be crucial when reliable data to populate the model are scarce. Future research is needed test the applicability of the proposed framework to the Cocody Bay in Abidjan, Côte d'Ivoire.

\section{Acknowledgements}

We would like to thank Dr. Sébastien Koffi Ouffoue and Miss Nina Sosthenes, from the CIAPOL, Abidjan, Côte d'Ivoire, for their assistance in accessing relevant information on the pollution of the Cocody bay. We would also like to thank Professor Adja Augustin Anasse, from the Université Alassane Ouattara, Bouaké, Côte d'Ivoire, for his expert advice, which were crucial to the finalization of this work.

\section{Role of the funding source}

This research was an academic undertaking and did not benefit from any funding.

\section{References}

Addiscott, T.M., Whitmore, A.P., Powlson, D.S., 1991. "Farming, Fertilizers and the Nitrate Problem".CAB International, Leaper and Gard, Bristol. 170 pp.

AnohK. P., 2001.' 'Lagune Ebrié de 1955 à 1998 : pollution des eaux et encombrement des baie urbaines de l'agglomération d'Abidjan'. In GeoTrope \#1. Ed PUCI. pp 62-78

Arrêté \#01164/MINEEF/CIAPOL/SDIIC du 4/11/2008, "'Portant Réglementation des Rejets et Emissions des Installations Classées pour la Protection de l'Environnement'. MINEEF/CIAPOL/SDIIC 
Beaudoin, N., Makowski, D., Parnaudeau, V., Parisseaux, B., Wallach, D., Mary, B., Meynard, J.M., 1998. 'Evaluation de l'impact economique et environnemental de la mesure agro-environnementale : réduction d'intrants au moyen de modèles agronomiques". Rapp. Minist.Agric.fran. 79 pp.

Beaudoin, N., Makowski, D., Parnaudeau, V., Mary, B., 1999.' Impact of agricultural scenarios on nitrate pollution at the catchment scale'.10th Nitrogen Workshop. Royal Veterinary and Agricultural University, Copenhagen.

Brisson, N., Mary, B., Ripoche, D., Jeuffroy, M.-H., Ruget, F., Gate, P., Devienne, F., Antonioletti, R., Dqrr, C., Nicoullaud, B., Richard, G., Beaudoin, N., Recous, S., Tayot, X., Plenet, D., Cellier, P., Machet, J.M., Meynard, J.M., Delecolle, R.,1998. ' $S T I C S:$ a generic model for the simulation of crops and their water and nitrogen balance: I. Theory and parametrization applied to wheat and corn'. Agronomie 18, 311-346.

Bureau National d'Etudes Techniques et de Développement (BNETD), 2011. 'Plan d'actions pour la dépollution et la réhabilitation de la baie de Cocody'. MINIE/MINEDD/MCLAU

Bystrom, O., Andersson, H., Gren, I.M., 2000. ' 'Economic criteria for using wetlands ass nitrogen sinks under uncertainty', Ecol. Econ. 35, 35-45.

De Haen, H., 1990. ' 'Economic aspects of controlling the nitrate contamination of drinking water’'.In: Calvet, R. (Ed.), Nitrates- Eau-Agriculture. INRA, Versailles, pp. 23-40.

Gorres, J., Gold, A.J., 1996. ' 'Incorporating spatial variability into GIS to estimate nitrate leaching at the aquifer scale'’. J. Environ. Qual. 25, 491-498.

Guillemin, C., Roux, J.C., 1992. 'Pollution des eaux souterraines en France'. BRGM, Orleans. 262 pp.

Hardaker, J.B., Pandey, S., Patten, L.H., 1991. ''Farm planning under uncertainty: a review of alternative programming models''. Rev. Mark. Agric. Econ. 59, 9-22. 
Justes, E., Mary, B., Nicolardot, B., 1999. 'Comparing the effectiveness of radish cover crop, oilseed rape volunteers and oilseed rape residues incorporation for reducing nitrate leaching'’. Nutr.Cycl.Agroecosyst. 55, 207-220.

Kampas, A., White, B., 2003. 'Probabilistic programming for nitrate pollution control: comparing different probabilistic constraint approximations',.Eur. J. Oper. Res. 147, $217-$ 228.

Lacroix, A., Balduchi, F., 1995. Le traitement des nitrates de l'eau potable. Bilan e'conomique perspectives. Tech. Sci. Me'thodes 12, 923-929.

Lacroix, A., Beaudoin, N., Makowski, D., 2005. ' Agricultural water non-point pollution control under uncertainty and climate variability'. Ecological Economic, 53, 115-127.

Laurent, F., Mary, B., 1992.'Management of nitrogen in farming systems and the prevention of nitrate leaching''.Asp. Appl. Biol. 30, 45-62.

Makowski, D., Wallach, D., Meynard, J.M., 1999. ' 'Models of yield, grain protein and residual mineral $\mathrm{N}$ responses to applied $\mathrm{N}$ for winter wheat'. Agron. J. 91, 377-385.

Makowski, D., Wallach, D., Meynard, J.-M., 2001. 'Statistical methods for predicting the responses to applied $\mathrm{N}$ and for calculating optimal $\mathrm{N}$ rates' 'Agron. J. 93, 531-539.

Mary, B., Beaudoin, N., Benoit, M., 1997. 'Prévention de la pollution nitrique a l'échelle du bassin d'alimentation en eau'. In: Lemaire, G., Nicolardot, B. (Eds.), Martrise de l'azote dans les agrosystèmes. INRA, Paris, pp. 289-312.

Mc Sweeny, W.T., Shortle, J.S., 1990. '’Probabilistic cost effectiveness in agricultural nonpoint pollution control'’. South. J. Agric. Econ., 95-104.

MINEDD/DITE, 2011. 'Compte rendu de réunion relative à la réhabilitation de la baie de Cocody et du Banco",

(C) 2016 by the author; licensee Preprints, Basel, Switzerland. This article is an open access article distributed under the terms and conditions of the Creative Commons by Attribution (CC-BY) license (http://creativecommons.org/licenses/by/4.0/). 